CLINICAL STUDY

\title{
Physiologic variance of corticotropin affects diagnosis in adrenal vein sampling
}

\author{
Masayuki Tanemoto, Takehiro Suzuki, Michiaki Abe, Takaaki Abe and Sadayoshi Ito \\ Division of Nephrology, Hypertension E Endocrinology, Department of Medicine, Graduate School of Medicine, Tohoku University, \\ 1-1 Seiryo-cho, Aoba-ku, Sendai, Miyagi 980-8574, Japan \\ (Correspondence should be addressed to M Tanemoto; Email: mtanemoto-tky@umin.ac.jp)
}

\begin{abstract}
Objective: Differentiating unilateral form from bilateral is a critical diagnostic step in primary aldosteronism (PA), for which adrenal vein sampling (AVS) is accepted to be the most reliable. However, variance of corticotropin could affect the diagnosis in AVS.

Design and methods: We conducted simultaneous bilateral AVS on ten biochemically diagnosed PA cases, and used the aldosterone-to-cortisol ratio $(\mathrm{A} / \mathrm{C})$ of the samples for the diagnosis. The diagnosis by AVS after a low-dose $(0.1 \mu \mathrm{g})$ ACTH stimulation, which can provoke maximum-physiologic corticotropic response, was compared with those before the stimulation and after the standard-dose $(250 \mu \mathrm{g})$ ACTH stimulation.

Results: In half of the cases, the low-dose pre-stimulation affected the diagnosis. In four out of ten cases, the side-to-side ratios of $\mathrm{A} / \mathrm{C}$ were changed in the basal/low-dose/standard-dose AVS as $6.62 / 2.46 / 0.63,2.13 / 0.41 / 0.14,1.88 / 2.38 / 2.40$, and $1.96 / 2.27 / 1.90$ respectively. In three out of ten cases, the adrenal vein to the matching inferior vena cava ratio of $\mathrm{A} / \mathrm{C}$ was also changed across 1 , the cut-off to indicate suppression of aldosterone secretion. Additionally, the confirmation of successful sampling was difficult in five out of ten and two out of ten cases of the basal and low-dose AVS respectively, whereas it was easy in all the cases of the standard-dose AVS.

Conclusions: The diagnosis in the basal AVS could be affected by the physiologic fluctuation of ACTH at relatively high prevalence. The basal AVS would be unreliable to differentiate two forms of PA.
\end{abstract}

European Journal of Endocrinology 160 459-463

\section{Introduction}

Primary aldosteronism (PA) is recognized as a common cause of secondary hypertension, and is generally caused by either aldosterone-producing adenoma (commonly unilateral) or idiopathic hyperaldosteronism (commonly bilateral) (1-3). Differentiation of unilateral form from bilateral is a critical step in the diagnosis of PA, because the unilateral form is potentially curable by unilateral adrenalectomy and the bilateral form is generally treated with the administration of mineralocorticoid receptor antagonists.

Adrenal vein sampling (AVS) is the widely accepted way for differentiation, but the methodology used for AVS is different among different centers (3). Independent of the methodological difference, the following points are critical to perform adrenalectomy: i) confirmation of successful sampling and ii) certainty of the laterality of aldosterone hypersecretion. Adrenocortical hormones are under the effect of ACTH, and AVS without sufficient pre-stimulation could be affected by its fluctuation (4-6). Therefore, some investigators advocated pre-stimulation with synthetic corticotropin to ensure active adrenal secretion at the time of AVS
(7-10). However, others expressed concern that the prestimulation could abolish the laterality of aldosterone secretion (11); the dose of synthetic corticotropin generally used for the pre-stimulation is extra-physiologically high $(12,13)$, and the exaggerated corticotropic response by it could conceal the laterality.

In this study, we performed AVS in three different conditions: before any artificial stimulation, after stimulation by a low-dose $(0.1 \mu \mathrm{g})$ cosyntropin, which can provoke maximum-physiologic corticotropic response, and after stimulation by the standard-dose $(250 \mu \mathrm{g})$ cosyntropin. We found that confirmation of successful sampling is difficult without sufficient prestimulation and that physiologically attainable corticotropin could affect the diagnosis in the AVS.

\section{Subjects and methods}

\section{Subjects}

The hypertensive patients with plasma renin activity (PRA; normal range: $0.2-2.7 \mathrm{ng} / \mathrm{ml}$ per $\mathrm{h})<1.0 \mathrm{ng} / \mathrm{ml}$ per $\mathrm{h}$ and plasma aldosterone concentration (PAC; 
normal range: $3.6-24 \mathrm{ng} / \mathrm{dl})>12 \mathrm{ng} / \mathrm{dl}$ with the PACto-PRA ratio (PAC/PRA) $>40$ were further evaluated $(14,15)$. After the withdrawal of $\beta$-blockers and diuretics for at least 4 weeks, a captopril test was performed; PRA and PAC were measured at 60 or $90 \mathrm{~min}$ after an oral administration of $50 \mathrm{mg}$ of captopril, and PAC/PRA was calculated (15). The patients with PAC/PRA $>30$ in the captopril test were given the biochemical diagnosis of PA (3). We enrolled ten of these cases in the study. The study protocol was approved by the ethics committee of our hospital, and informed consent was obtained from all the patients.

\section{Simultaneous bilateral AVS}

Catheterization of both femoral veins was performed in all the cases in the early afternoon (1300$1400 \mathrm{~h}$ ). Blood samples of AVS for the measurement of PAC and plasma cortisol concentration were simultaneously obtained from both the AV and the infrarenal inferior vena cava (IVC; basal AVS). A lowdose cosyntropin $(0.1 \mu \mathrm{g})$ was administered as an i.v. bolus, and the sampling was repeated 15 min later (low-dose AVS). After the low-dose AVS, the standard-dose cosyntropin $(250 \mu \mathrm{g})$ was administered and the sampling was repeated $15 \mathrm{~min}$ later (standard-dose AVS). The patients were kept supine throughout the AVS procedure.

\section{Chemical and hormonal assays}

The serum creatinine concentration ( $\mathrm{sCr}$ ) and PRA were enzymatically measured. Plasma cortisol concentration was measured with a commercially available kit (Fluorescence Polarization Immunoassay, TDX/TDXFLX Cortisol; Abbott Japan Co. Ltd). The intra-assay coefficients of variation were 7.54-7.56, 2.94-3.20, and $1.98-2.30 \%$ for its low, medium, and high levels respectively. PAC was measured using commercial laboratory test services (Mitsubishi Chemical Medience, Tokyo, Japan). The reported intra-assay coefficients of variation were $8.3,3.9$, and $1.8 \%$ for PAC of $10.3,33.6$, and $73.2 \mathrm{ng} / \mathrm{dl}$ respectively.

\section{Diagnosis in AVS}

We used the PAC-to-plasma cortisol concentration ratio $(\mathrm{A} / \mathrm{C})$ of AVS samples for the diagnosis in AVS. The ratio of $\mathrm{A} / \mathrm{C}$ in one $\mathrm{AV}$ to the other (the side-to-side ratio) was used to judge the laterality of aldosterone secretion; the ratios $>4$ and $>2$ were taken as conservative and aggressive cut-offs respectively $(3,7-9,16)$. The AV-to-IVC ratio (AV/IVC) of $\mathrm{A} / \mathrm{C}<1$ was taken as the suppression of aldosterone secretion for the side $(7,8,10)$.

\section{Results}

\section{Baseline characteristics}

The baseline characteristics of the patients are summarized in Table 1. Except for one case who had an $\mathrm{sCr}$ of $106.1 \mu \mathrm{mol} / \mathrm{l}$, all the other cases had preserved renal function $(\mathrm{sCr} \leq 88.4 \mu \mathrm{mol} / \mathrm{l}$, normal range: $35.4-88.4 \mu \mathrm{mol} / \mathrm{l})$. Half of the cases $(5 / 10)$ had hypokalemia (serum potassium concentration $\leq 3.4 \mathrm{mmol} / \mathrm{l}$, normal range: $3.5-4.8 \mathrm{mmol} / \mathrm{l}$ ), and four out of five of them had PAC $>24 \mathrm{ng} / \mathrm{dl}$. All the cases who did not have hypokalemia had PAC $<24 \mathrm{ng} / \mathrm{dl}$. The plasma corticotropin was less than its upper normal limit (normal range: $9-52 \mathrm{pg} / \mathrm{ml}$ ).

\section{Aldosterone and cortisol concentration in AVS}

The results of AVS are shown in Table 2. The low-dose pre-stimulation increased PAC and plasma cortisol concentration in the AV samples except for one sample, and the standard-dose pre-stimulation increased them in all the AV samples. The pre-stimulation increased the AV/IVC of plasma cortisol concentration in all the AV samples, and the ratios were $>1.6,>1.9$, and $>19$ in the basal, low-dose, and standard-dose AVS respectively.

\section{Laterality of aldosterone secretion}

The side-to-side ratio of $\mathrm{A} / \mathrm{C}$ is summarized in Table 3. Seven cases had the ratio in the basal AVS higher than the conservative cut-off $(>4)$. In six of them, the ratio remained $>4$ in both the low- and standard-dose AVS. In the other case with the ratio of 6.62 (case 1), however, the ratio decreased to 2.46 (lower than the conservative cut-off, but higher than the aggressive cutoff) in the low-dose AVS. It decreased further to 0.63 and the laterality was changed in the standard-dose AVS, but its reciprocal ratio was lower than the aggressive cut-off $(<2)$.

Three cases had the ratio in the basal AVS lower than the conservative cut-off $(<4)$. In one case with the ratio higher than the aggressive cut-off (2.13, case 2$)$, the laterality was changed in the low-dose AVS and the reciprocal ratio was 2.47 (lower than the conservative

Table 1 Baseline characteristics of patients.

\begin{tabular}{ll}
\hline Number $(\%$ female) & $10(30)$ \\
Age (years) & $55 \pm 13(34-71)$ \\
$\mathrm{sCr}(\mu \mathrm{mol} / \mathrm{l})$ & $73.4 \pm 15.6(35.4-106.1)$ \\
$\mathrm{sK}^{+}(\mathrm{mmol} / \mathrm{l})$ & $3.4 \pm 0.6(2.3-4.0)$ \\
$\mathrm{ACTH}(\mathrm{pg} / \mathrm{ml})$ & $16.1 \pm 7.2(6.2-32.7)$ \\
$\mathrm{PRA}(\mathrm{ng} / \mathrm{ml}$ per hour $)$ & $0.2 \pm 0.1(0.1-0.4)$ \\
$\mathrm{PAC}(\mathrm{ng} / \mathrm{dl})$ & $33.0 \pm 21.7(13.5-66.8)$ \\
PAC/PRA & $258 \pm 220(55.5-668)$
\end{tabular}

Values are expressed as mean \pm S.D. with their distribution given in parentheses, where appropriate. $\mathrm{sCr}$, serum creatinine concentration; $\mathrm{sK}^{+}$; serum potassium concentration; PRA, plasma renin activity; PAC, plasma aldosterone concentration. 
Table 2 Results of adrenal vein sampling (AVS).

\begin{tabular}{|c|c|c|c|c|c|c|c|}
\hline \multirow[b]{2}{*}{ Case } & & \multicolumn{2}{|c|}{ Basal } & \multicolumn{2}{|c|}{ Low dose } & \multicolumn{2}{|c|}{ Standard dose } \\
\hline & & PAC & Cortisol & PAC & Cortisol & PAC & Cortisol \\
\hline \multirow[t]{2}{*}{1} & $\mathrm{R} / \mathrm{L}$ & $1558 / 177$ & $22.1 / 16.6$ & $1939 / 869$ & $128 / 141$ & $3643 / 3559$ & $925 / 565$ \\
\hline & IVC & 9.7 & 3.7 & 16.6 & 7.1 & 25.9 & 22.0 \\
\hline \multirow[t]{2}{*}{2} & $\mathrm{R} / \mathrm{L}$ & $401 / 136$ & 18.4/13.2 & $317 / 508$ & $171 / 111$ & $648 / 7680$ & $520 / 880$ \\
\hline & IVC & 11.8 & 2.8 & 11.9 & 5.5 & 21.6 & 13.9 \\
\hline \multirow[t]{2}{*}{3} & $\mathrm{R} / \mathrm{L}$ & $61.7 / 20.3$ & $84.0 / 54.2$ & $594 / 221$ & $341 / 288$ & $2518 / 896$ & 1159/785 \\
\hline & IVC & 6.2 & 15.4 & 4.2 & 15.4 & 10.6 & 23.6 \\
\hline \multirow[t]{2}{*}{4} & $\mathrm{R} / \mathrm{L}$ & $34.5 / 53.8$ & $16.8 / 13.9$ & $223 / 244$ & $115 / 53$ & $1310 / 2623$ & $621 / 531$ \\
\hline & IVC & 9.3 & 6.9 & 11.2 & 8.2 & 16.4 & 18.9 \\
\hline \multirow[t]{2}{*}{5} & $\mathrm{R} / \mathrm{L}$ & $498 / 17.5$ & $18.2 / 17.1$ & $2026 / 216$ & $244 / 174$ & $4432 / 592$ & $443 / 492$ \\
\hline & IVC & 10.6 & 7.2 & 17.9 & 15.3 & 27 & 23.7 \\
\hline \multirow[t]{2}{*}{6} & $\mathrm{R} / \mathrm{L}$ & $318 / 8.7$ & $26 / 27$ & $386 / 8.5$ & $28.4 / 26$ & $7667 / 447$ & $1051 / 735$ \\
\hline & IVC & 7.5 & 15.7 & 8.1 & 13.5 & 20 & 25.5 \\
\hline \multirow[t]{2}{*}{7} & $\mathrm{R} / \mathrm{L}$ & $2467 / 52.7$ & $19.2 / 15.6$ & $2269 / 125$ & $20.9 / 304$ & $10853 / 458$ & $688 / 801$ \\
\hline & IVC & 61.3 & 5.5 & 72 & 10.1 & 80.0 & 18.2 \\
\hline \multirow[t]{2}{*}{8} & $\mathrm{R} / \mathrm{L}$ & $563 / 17.7$ & 17.9/17.1 & $1543 / 74.8$ & $359 / 109$ & $20006 / 373$ & $521 / 438$ \\
\hline & IVC & 13.7 & 10.5 & 23.0 & 14.7 & 46.0 & 23.0 \\
\hline \multirow[t]{2}{*}{9} & $\mathrm{R} / \mathrm{L}$ & $942 / 44.4$ & $33.3 / 40.4$ & $1964 / 177$ & $404 / 424$ & $3531 / 352$ & $555 / 823$ \\
\hline & IVC & 42.9 & 8.9 & 45.5 & 15.0 & 60.5 & 26.2 \\
\hline \multirow[t]{2}{*}{10} & $\mathrm{R} / \mathrm{L}$ & $34.9 / 2904$ & $20.7 / 17.7$ & $130 / 4001$ & $275 / 362$ & $475 / 8451$ & $1354 / 1071$ \\
\hline & IVC & 39.6 & 2.6 & 51.3 & 7.6 & 79.5 & 25.5 \\
\hline
\end{tabular}

PAC, plasma aldosterone concentration (ng/dl); cortisol, plasma cortisol concentration ( $\mu \mathrm{g} / \mathrm{dl})$; R, right adrenal vein; L, left adrenal vein; IVC, inferior vena cava.

cut-off, but higher than the aggressive cut-off). The reciprocal ratio increased further to 7.01, higher than the conservative cut-off, in the standard-dose AVS. The other two cases (cases 3 and 4) had the ratio in the basal AVS lower than the aggressive cut-off $(<2)$. In these cases, the laterality was not changed, but the ratio increased to $>2$ in the low-dose AVS; the ratios in the basal/low-dose/standard-dose AVS were $1.88 / 2.38 / 2.40$ and $1.96 / 2.27 / 1.90$ respectively.

\section{Suppression of aldosterone secretion}

The suppression of aldosterone secretion, which was indicated by the $\mathrm{AV} / \mathrm{IVC}$ of $\mathrm{A} / \mathrm{C}<1$, was also changed by the pre-stimulation in three cases (Table 4). Two cases (cases 3 and 5), which had the ratio of one side $<1$ in the basal AVS, had the ratio of the both sides $>1$ in both the low- and standard-dose AVS. Conversely, one case

Table 3 The side-to-side ratio of aldosterone-to-cortisol ratio.

\begin{tabular}{lllll}
\hline Case & & Basal & Low dose & Standard dose \\
\hline 1 & $\mathrm{R} / \mathrm{L}(\mathrm{L} / \mathrm{R})$ & $6.62(0.15)$ & $2.46(0.41)$ & $0.63(1.60)$ \\
2 & $\mathrm{R} / \mathrm{L}(\mathrm{L} / \mathrm{R})$ & $2.13(0.47)$ & $0.40(2.47)$ & $0.14(7.01)$ \\
3 & $\mathrm{R} / \mathrm{L}(\mathrm{L} / \mathrm{R})$ & $1.96(0.51)$ & $2.27(0.44)$ & $1.90(0.53)$ \\
4 & $\mathrm{R} / \mathrm{L}(\mathrm{L} / \mathrm{R})$ & $0.55(1.88)$ & $0.42(2.38)$ & $0.42(2.40)$ \\
5 & $\mathrm{R} / \mathrm{L}(\mathrm{L} / \mathrm{R})$ & $26.8(0.04)$ & $6.68(0.15)$ & $8.32(0.12)$ \\
6 & $\mathrm{R} / \mathrm{L}(\mathrm{L} / \mathrm{R})$ & $37.9(0.03)$ & $41.5(0.02)$ & $12.0(0.08)$ \\
7 & $\mathrm{R} / \mathrm{L}(\mathrm{L} / \mathrm{R})$ & $38.1(0.03)$ & $264(0.00)$ & $27.6(0.04)$ \\
8 & $\mathrm{R} / \mathrm{L}(\mathrm{L} / \mathrm{R})$ & $30.3(0.03)$ & $6.25(0.16)$ & $45.1(0.02)$ \\
9 & $\mathrm{R} / \mathrm{L}(\mathrm{L} / \mathrm{R})$ & $25.7(0.04)$ & $11.7(0.09)$ & $14.9(0.07)$ \\
10 & $\mathrm{R} / \mathrm{L}(\mathrm{L} / \mathrm{R})$ & $0.01(97.7)$ & $0.04(23.4)$ & $0.04(22.5)$ \\
\hline
\end{tabular}

$\mathrm{A} / \mathrm{C}$, plasma aldosterone concentration $(\mathrm{ng} / \mathrm{dl}) /$ plasma cortisol concentration $(\mu \mathrm{g} / \mathrm{dl}) ; \mathrm{R}$, right adrenal vein; L, left adrenal vein. (case 2), which had the ratio of the both sides $>1$ in the basal AVS, had the ratio of one side $<1$ in both the low- and standard-dose AVS.

\section{Discussion}

In this study, we showed that the diagnosis in the basal AVS could be affected by the physiologic fluctuation of ACTH at the time of AVS. The fluctuation could affect either the laterality or the suppression of aldosterone secretion at relatively high prevalence. In addition, we also showed that confirmation of successful sampling is difficult without sufficient pre-stimulation.

In the basal AVS, six cases had PAC of IVC $<12 \mathrm{ng} / \mathrm{dl}$, although we selected cases of the baseline PAC $>12 \mathrm{ng} / \mathrm{dl}$. The usage of calcium channel blockers, which can suppress aldosterone secretion, could have decreased the PAC of IVC in the basal AVS, because we used them to control blood pressure during AVS (17, 18). It is also possible that the difference between the PAC of IVC in the basal AVS and the baseline PAC reflected the physiologic fluctuation of PAC, because we performed AVS in the early afternoon (5). Performance of AVS in the early afternoon is the main limitation of this study. The difference between the basal and lowdose AVS might have been decreased if AVS were performed in the morning when ACTH is generally higher than in the afternoon.

For the pre-stimulation, we used cosyntropin, a synthetic corticotropin, which has corticotropic potency as the natural corticotropin (19). A bolus injection of $0.1 \mu \mathrm{g}$ cosyntropin is expected to elevate its plasma concentration to $\sim 200 \mathrm{pg} / \mathrm{ml}$ (12). The insulin 
Table 4 The adrenal vein/inferior vena cava of aldosteroneto-cortisol ratio.

\begin{tabular}{lllll}
\hline Case & & Basal & Low dose & Standard dose \\
\hline 1 & $\mathrm{R} / \mathrm{L}$ & $27.0 / 4.07$ & $6.54 / 2.66$ & $3.39 / 5.42$ \\
2 & $\mathrm{R} / \mathrm{L}$ & $5.26 / 2.47$ & $0.85 / 2.10$ & $0.85 / 5.63$ \\
3 & $\mathrm{R} / \mathrm{L}$ & $1.83 / 0.93$ & $6.28 / 2.81$ & $4.84 / 2.54$ \\
4 & $\mathrm{R} / \mathrm{L}$ & $1.52 / 2.87$ & $1.42 / 3.37$ & $2.44 / 5.70$ \\
5 & $\mathrm{R} / \mathrm{L}$ & $18.5 / 0.69$ & $7.08 / 1.06$ & $8.79 / 1.06$ \\
6 & $\mathrm{R} / \mathrm{L}$ & $25.6 / 0.68$ & $22.7 / 0.55$ & $9.29 / 0.77$ \\
7 & $\mathrm{R} / \mathrm{L}$ & $11.5 / 0.30$ & $15.2 / 0.06$ & $3.60 / 0.13$ \\
8 & $\mathrm{R} / \mathrm{L}$ & $24.1 / 0.79$ & $2.75 / 0.44$ & $19.2 / 0.43$ \\
9 & $\mathrm{R} / \mathrm{L}$ & $5.87 / 0.23$ & $1.60 / 0.14$ & $2.79 / 0.19$ \\
10 & $\mathrm{R} / \mathrm{L}$ & $0.11 / 10.8$ & $0.07 / 1.63$ & $0.11 / 2.53$ \\
\hline
\end{tabular}

$\mathrm{AV}$, adrenal vein; IVC, inferior vena cava; A/C plasma aldosterone concentration $(\mathrm{ng} / \mathrm{dl}) /$ plasma cortisol concentration $(\mu \mathrm{g} / \mathrm{dl})$; R, right adrenal vein; $L$, left adrenal vein.

hypoglycemic test, an acknowledged test to provoke maximum physiologic response of the pituitary-adrenal axis, can elevate plasma ACTH concentration to 100-

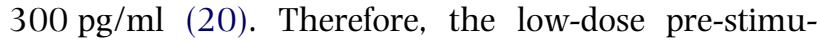
lation is thought to induce the maximum-physiologic but not supra-physiologic corticotropic response. Supporting this notion, the plasma cortisol concentration in the low-dose AVS was lower than its matching concentration in the standard-dose AVS.

After the low-dose AVS, we conducted the standarddose AVS consecutively. The preceding stimulation could have modified the adrenal response to the following stimulation. However, the preceding low-dose AVS is not thought to have significantly modified the following standard-dose AVS in the present cases, because the adrenal response in the standard-dose AVS was several times higher than that in the low-dose AVS. The preserved adrenal response after the preceding $0.5 \mu \mathrm{g}$ cosyntropin stimulation is also reported; the response to $250 \mu \mathrm{g}$ stimulation after the preceding $0.5 \mu \mathrm{g}$ stimulation is more than half of its maximum response (13).

The AV/IVC ratio of plasma cortisol concentration is widely used as an index for successful sampling. Its values from $>1.1$ to $>5$ are used for the judgment with lower values for the basal AVS than the pre-stimulated AVS $(7,11,21,22)$; the ratio $>3$ and $>5$ can be considered as conservative cut-offs for the former and the latter respectively. Using these conservative cut-offs, 9 out of 20 of the basal AVS samples and 3 out of 20 of the low-dose AVS samples are taken as unsuccessful, whereas all the standard-dose AVS samples are taken as successful. Consequently, only in half of the present cases, all three sets of AVS were taken successful by the conservative cut-offs. However, we verified the position of the catheter tip in each sampling by gentle injection of a small amount of contrast medium, and confirmed accomplishment of three sets of AVS at the same position in each case. Therefore, the result of basal and low-dose AVS samples being taken as unsuccessful by the conservative cut-offs indicates difficulty in confirming successful sampling without sufficient pre-stimulation. Difficulty in confirming successful sampling without pre-stimulation is also reported; nearly half of the basal AVS samples that the radiologist considered successful do not have the ratio $>3$ (21).

Unilateral form of aldosterone secretion is generally indicated in two ways: (i) laterality of secretion, which is judged by the side-to-side ratio of A/C either $>4-5$ (3, $7-9$ ) or $>2$ (16) and (ii) suppression of secretion from the other side, which is judged by the AV/IVC of $\mathrm{A} / \mathrm{C}<1$ $(7,8,10)$. The low-dose pre-stimulation affected either the laterality or the suppression in half of the present cases. In a subset of the cases in whom all three sets of AVS were taken as successful by the conservative cutoffs, the low-dose pre-stimulation also affected either the laterality or the suppression in two out of five cases. These results indicate that the diagnosis in the basal AVS is unreliable; the physiologic fluctuation of ACTH could change the diagnosis in the basal AVS (4). Supporting this notion, we experienced wide casedependent difference of the basal ACTH stimulation (6).

Slight difference of each ratio is practically indistinguishable due to the variation of the intra-assay coefficients for PAC and plasma cortisol concentration, and the diagnosis in cases 3,4 , and 5 could be taken the same in all three types of AVS. However, the diagnosis in cases 1 and 2 could not be taken the same. The prestimulation amply changed the side-to-side ratio of $\mathrm{A} / \mathrm{C}$ across the cut-offs, although both cases could be taken as bilateral lack of suppression independent of the prestimulation. These controversial cases did not undergo adrenalectomy, because they could be bilateral forms. Without histological confirmation, we could not determine which set of AVS was accurate, but we think that the diagnostic AVS should be performed under constant conditions such as after sufficient ACTH stimulation. Difficulty in confirmation of successful sampling without sufficient pre-stimulation also supports the necessity of ACTH stimulation in the diagnostic AVS.

In summary, the results of this study indicate that the physiologic fluctuation of ACTH can affect the diagnosis in the basal AVS. Although the enrollment was small, the high prevalence with diagnostic change by the physiologically attainable corticotropin indicates that the diagnosis in the basal AVS is unreliable in not a few cases. Difficulty in confirmation of successful sampling is another disadvantage of the basal AVS. Therefore, AVS with sufficient pre-stimulation, such as the standard-dose AVS, is preferable, especially when the basal AVS is difficult to be taken successful.

\section{Declaration of interest}

There is no conflict of interest that could be perceived as prejudicing the impartiality of the research reported.

\section{Funding}

This study was supported by the grants from the Ministry of Education, Culture, Sports, Science and Technology of Japan, and from the Salt Science Research Foundation (no. 0734 and 08C2). 


\section{References}

1 Mattsson C \& Young WF Jr. Primary aldosteronism: diagnostic and treatment strategies. Nature Clinical Practice. Nephrology 20062 $198-208$.

2 Schirpenbach C \& Reincke M. Primary aldosteronism: current knowledge and controversies in Conn's syndrome. Nature Clinical Practice. Endocrinology and Metabolism 20073 220-227.

3 Funder JW, Carey RM, Fardella C, Gomez-Sanchez CE, Mantero F, Stowasser M, Young WF Jr \& Montori VM. Case detection, diagnosis, and treatment of patients with primary aldosteronism: an endocrine society clinical practice guideline. Journal of Clinical Endocrinology and Metabolism 200893 3266-3281.

4 Siragy HM, Vieweg WV, Pincus S \& Veldhuis JD. Increased disorderliness and amplified basal and pulsatile aldosterone secretion in patients with primary aldosteronism. Journal of Clinical Endocrinology and Metabolism $19958028-33$.

5 Kem DC, Weinberger MH, Gomez-Sanchez C, Kramer NJ, Lerman R, Furuyama S \& Nugent CA. Circadian rhythm of plasma aldosterone concentration in patients with primary aldosteronism. Journal of Clinical Investigation $1973 \mathbf{5 2}$ 2272-2277.

6 Tanemoto M, Satoh F, Abe T \& Ito S. To stimulate or not to stimulate: is adrenocorticotrophic hormone testing necessary, or not? - round 2 Journal of Hypertension 200725 1517-1518.

7 Magill SB, Raff H, Shaker JL, Brickner RC, Knechtges TE, Kehoe ME \& Findling JW. Comparison of adrenal vein sampling and computed tomography in the differentiation of primary aldosteronism. Journal of Clinical Endocrinology and Metabolism $2001 \mathbf{8 6}$ 1066-1071.

8 Phillips JL, Walther MM, Pezzullo JC, Rayford W, Choyke PL, Berman AA, Linehan WM, Doppman JL \& Gill JR Jr. Predictive value of preoperative tests in discriminating bilateral adrenal hyperplasia from an aldosterone-producing adrenal adenoma. Journal of Clinical Endocrinology and Metabolism $2000 \mathbf{8 5}$ $4526-4533$.

9 Young WF, Stanson AW, Thompson GB, Grant CS, Farley DR \& van Heerden JA. Role for adrenal venous sampling in primary aldosteronism. Surgery 2004136 1227-1235.

10 Doppman JL \& Gill JR Jr. Hyperaldosteronism: sampling the adrenal veins. Radiology $1996198309-312$.

11 Rossi GP, Ganzaroli C, Miotto D, De Toni R, Palumbo G, Feltrin GP, Mantero F \& Pessina AC. Dynamic testing with high-dose adrenocorticotrophic hormone does not improve lateralization of aldosterone oversecretion in primary aldosteronism patients. Journal of Hypertension 200624 371-379.

12 Mayenknecht J, Diederich S, Bahr V, Plockinger U \& Oelkers W. Comparison of low and high dose corticotropin stimulation tests in patients with pituitary disease. Journal of Clinical Endocrinology and Metabolism $1998 \mathbf{8 3} 1558-1562$.
13 Arvat E, Di Vito L, Lanfranco F, Maccario M, Baffoni C, Rossetto R, Aimaretti G, Camanni F \& Ghigo E. Stimulatory effect of adrenocorticotropin on cortisol, aldosterone, and dehydroepiandrosterone secretion in normal humans: dose-response study. Journal of Clinical Endocrinology and Metabolism $2000 \mathbf{8 5}$ 3141-3146.

14 Giacchetti G, Ronconi V, Lucarelli G, Boscaro M \& Mantero F. Analysis of screening and confirmatory tests in the diagnosis of primary aldosteronism: need for a standardized protocol. Journal of Hypertension $2006 \mathbf{2 4} 737-745$.

15 Seiler L, Rump LC, Schulte-Monting J, Slawik M, Borm K, Pavenstadt H, Beuschlein F \& Reincke M. Diagnosis of primary aldosteronism: value of different screening parameters and influence of antihypertensive medication. European Journal of Endocrinology $2004150329-337$.

16 Rossi GP, Sacchetto A, Chiesura-Corona M, De Toni R, Gallina M, Feltrin GP \& Pessina AC. Identification of the etiology of primary aldosteronism with adrenal vein sampling in patients with equivocal computed tomography and magnetic resonance findings: results in 104 consecutive cases. Journal of Clinical Endocrinology and Metabolism 200186 1083-1090.

17 Nadler JL, Hsueh W \& Horton R. Therapeutic effect of calcium channel blockade in primary aldosteronism. Journal of Clinical Endocrinology and Metabolism 198560 896-899.

18 Veglio F, Pinna G, Bisbocci D, Rabbia F, Piras D \& Chiandussi L. Efficacy of nicardipine slow release (SR) on hypertension, potassium balance and plasma aldosterone in idiopathic aldosteronism. Journal of Human Hypertension 19904 579-582.

19 Landon J, James VH, Cryer RJ, Wynn V \& Frankland AW. Adrenocorticotropic effects of a synthetic polypeptide-Beta 124-corticotropin - in man. Journal of Clinical Endocrinology and Metabolism 196424 1206-1213.

20 Oelkers W. The role of high- and low-dose corticotropin tests in the diagnosis of secondary adrenal insufficiency. European Journal of Endocrinology 1998139 567-570.

21 Harvey A, Kline G \& Pasieka JL. Adrenal venous sampling in primary hyperaldosteronism: comparison of radiographic with biochemical success and the clinical decision-making with 'less than ideal' testing. Surgery 2006140 847-853.

22 Espiner EA, Ross DG, Yandle TG, Richards AM \& Hunt PJ. Predicting surgically remedial primary aldosteronism: role of adrenal scanning, posture testing, and adrenal vein sampling. Journal of Clinical Endocrinology and Metabolism $2003 \mathbf{8 8}$ 3637-3644.

Received 27 November 2008

Accepted 28 November 2008 